\title{
The COD Removal of Lime and Subsequent Acid Pretreated Partially Stabilised Leachate via Granular-Activated Carbon
}

\author{
Lennevey Kinidi $(\mathbb{D}$ and Shanti Faridah Salleh \\ Department of Chemical Engineering and Energy Sustainability, Faculty of Engineering, Universiti Malaysia Sarawak, \\ Kota Samarahan 94300, Sarawak, Malaysia
}

Correspondence should be addressed to Lennevey Kinidi; lennybb93@outlook.com

Received 4 December 2019; Revised 18 February 2020; Accepted 28 April 2020; Published 15 May 2020

Academic Editor: Deepak Kunzru

Copyright (C) 2020 Lennevey Kinidi and Shanti Faridah Salleh. This is an open access article distributed under the Creative Commons Attribution License, which permits unrestricted use, distribution, and reproduction in any medium, provided the original work is properly cited.

\begin{abstract}
Background. This paper investigated the effectiveness of lime treatment and subsequent acid precipitation $\left(\right.$ using $\left.\mathrm{H}_{2} \mathrm{SO}_{4}\right)$ as a pretreatment of partially stabilised leachate. This study obtained high removal efficiencies (>70\%) from the lime and acid pretreated partially stabilised leachate. The treatment of this wastewater with $10 \mathrm{~g} / \mathrm{L}$ dosage of optimum lime $(\mathrm{pH} 12)$ at $25^{\circ} \mathrm{C}$ had led to the $41 \%$ COD elimination in the initial stages of pretreatment. Subsequent pH adjustment using $1 \mathrm{~N}$ sulfuric acid and granular-activated carbon adsorption in general revealed more than $92 \%$ removal of the $4 \mathrm{~g} / \mathrm{L}$ of carbon dosage. Therefore, the results revealed that the adsorption of COD on the GAC stemmed from the kinetics rate of the pseudo-second-order.
\end{abstract}

\section{Introduction}

Landfill leachate is multifaceted wastewater, which consists of a large amount of biodegradable and nonbiodegradable matter [1]. The landfill that is built without appropriate line and collection systems leads to groundwater pollution which has an adverse impact on the environment. Today, the landfill process for leachate management is often a collective technique. Therefore, the efficiency of a leachate treatment is dependent on its characteristics. The coagulation and adsorption processes are possibly viable for a partially stabilised leachate. The removal of COD revealed the highest (50-56\%) record of achievement with the partially stabilised leachate whereas $10-25 \%$ of achievement was with the young leachates [2].

The inclusion of lime had eliminated organic matter with high molecular mass greater than 50,000. This fraction is relatively present in low concentrations of leachate from young fills and almost absent from old fills. Since the organic proportion of the 50,000 molecular weight had increased in the young fills and decreased in the older fills [3], lime treatment was a highly efficient procedure to treat the leachate from the partially stabilised leachate fills. Moreover, acid precipitation had efficaciously eliminated the COD from the laundry wastewater and paper mill wastewater $[4,5]$. Additionally, either $\mathrm{CO}_{2}$ or mineral acids were introduced to reduce the $\mathrm{pH}$. COD removal by adsorption via GAC offers a mature, simple, and cost-effective process with regard to the process of advanced oxidation. Although previous works of literature did not investigate the combined effect of lime and subsequent acid pretreated partially stabilised landfill leachate by using granular-activated carbon adsorption for COD removal, several researchers had studied the adsorptive elimination of medium-age landfill leachate via granular-activated carbon [6-8].

The research found that the effort to treat partially stabilised (BOD/COD: 0.1-0.5) landfill leachate solely via granular-activated carbon is expensive from an economic perspective [2]. Nonetheless, the present study examined the optimum use of activated carbon based on the expected preadsorption separation of humic and fulvic acid via lime treatment and how the adsorption onto the granular-activated carbon was enhanced by the addition of acid. This study examined the removal of COD via lime, the subsequent addition of sulfuric acid, and finally the use of GAC as an adsorbent. The addition of lime and sulfuric acid was used 
TABLE 1: Attributes of partially stabilised landfill leachate.

\begin{tabular}{lcc}
\hline \multirow{2}{*}{ Parameters } & \multicolumn{2}{c}{ Value } \\
& Range & Average \\
\hline $\mathrm{pH}$ & $8.25-8.44$ & 8.35 \\
$\mathrm{BOD} 5(\mathrm{mg} / \mathrm{L})$ & $200-600$ & 300 \\
$\mathrm{COD}(\mathrm{mg} / \mathrm{L})$ & $2000-3670$ & 2800 \\
Total suspended solids (mg/L) & $623-895$ & 738 \\
BOD/COD & $0.1-0.2$ & 0.11 \\
$\mathrm{UV}_{254}$ & $12.45-19.45 \mathrm{~cm}^{-1}$ & $15.92 \mathrm{~cm}^{-1}$ \\
\hline
\end{tabular}

in the pretreatment stage to adsorb. This study had also studied the impact of the numerous measurements such as lime dosage, primary $\mathrm{pH}$, contact time, and carbon dosage on the efficiency of adsorption. Additionally, experimental records were collected for the kinetic adsorption with an optimal $\mathrm{pH}$ lime dosage based on a wide range of adsorbent dosage. Besides, the kinetic adsorption of organic (expressed as COD) removal was explained. The kinetics explained the pace of the adsorption of the organic molecules on the granular-activated carbon surfaces, which determined the necessary contact time for the symmetry. Table 1 shows the attributes of the partially stabilised leachate in the present study.

\section{Materials and Methods}

2.1. Collection of Landfill Leachate. The present study utilised samples of landfill from the open dumpsite at Tapak Pelupusan Sampah Bau, Sarawak, Malaysia. The landfill leachate was collected on-site, transported, and stored in the $4^{\circ} \mathrm{C}$ refrigerator room until the experiment was carried out to reduce biological activity and chemical reactions.

2.2. Materials and Chemicals. The Bravo Green Sdn. Bhd had procured the GAC locally. The average particle size was $1.5 \mathrm{~mm}$. Meanwhile, the calcium oxide was purchased from Sigma-Aldrich Sdn. Bhd. Next, the sulfuric acid was purchased from Sigma-Aldrich, Germany. Finally, to achieve the required durability for the pretreatment, the sulfuric acid was diluted with distilled water.

\subsection{Adsorbent Characterizations}

2.3.1. Study of Textural Characteristics of the Adsorbent. The specific surface area and the porosity of the coconut granular-activated carbon were determined by $\mathrm{N}_{2}$ adsorption at $77 \mathrm{~K}$ via the BET.

2.3.2. FTIR Analysis. The surface of the coconut activated carbon functional groups was determined by the infrared spectra transmission from the Fourier transform spectrophotometer with the use of the Kbr pellets, which was made up of $0.5 \%$ delicately ground activated carbon samples.

2.3.3. Point of Zero Charges $\left(p H_{p z c}\right)$. The solid addition method was used to determine the $\mathrm{pH}_{\mathrm{pzc}}$ of the activated carbon. Therefore, $20 \mathrm{~mL}$ of the $0.1 \mathrm{M} \mathrm{KNO}_{3}$ was added to a sequence of $50 \mathrm{~mL}$ flasks. The primary $\mathrm{pH}$ of the solutions was attuned between 2 and 12 via $0.01 \mathrm{~N} \mathrm{HNO}_{3}$ or $\mathrm{NaOH}$. Next, $\mathrm{KNO}_{3}$ was included until the sum of the solution volume was $25 \mathrm{~mL}$ and the initial $\mathrm{pH}$ was evaluated and approximately $0.5 \mathrm{~g}$ of the activated carbon was added into each flask and capped. It was then stored for 2 days at ambient temperature with constant agitation (100 rpm). Next, this study measured the difference between the primary and concluding $\mathrm{pH}$ value, which was charted against the initial $\mathrm{pH}$. The point of intersection of the $\Delta \mathrm{pH}=0$ indicated the $\mathrm{pH}_{\mathrm{pzc}}$.

2.4. Analytical Methods. The characteristics of the wastewater such as $\mathrm{pH}, \mathrm{COD}, \mathrm{BOD}$, and TCLP were determined per APHA (2003). The absorption of ultraviolet at $2.54 \mathrm{~nm}$ ( $\mathrm{UV}_{254}$ absorbance) was quantified with a spectrophotometer (UV-1800 Shimadzu Spectrophotometer). Therefore, the samples of the raw leachate were tempered to produce a result within the parameter of recognition. The measurements of the UV were magnified by the parallel features of dilution to produce the values of the concluding numbers of the absorbance.

2.5. Experimental Studies. Firstly, lime and subsequent acid pretreatment were performed by adding $10 \mathrm{~g} / \mathrm{L}$ of lime dosage. Next, the precipitated wastewater was then purified with the Whatman filter paper via gravity purification. This was then followed by the addition of $1 \mathrm{~N}$ sulfuric acid to decrease the initial $\mathrm{pH}$ of the wastewater to a $\mathrm{pH}$ value of 2,4 , and 6. Next, a refrigerated orbital shaker was used to adsorb the batch. Therefore, the group experiments were executed at a stagnant shaker pace of $200 \mathrm{rpm}$. A total of $100 \mathrm{~mL} \mathrm{su-}$ pernatant wastewater was obtained from a $250 \mathrm{~mL}$ conical flask for each batch run. This wastewater consisted of the mass of a mixed adsorbent at a stationary shaker speed in the temperature-regulated orbital shaker, which is sustained at a fixed temperature. Next, samples were taken during the numerous intermissions to analyse the remains of the COD until the value of the symmetry was achieved.

There were different dosages of adsorbent, which ranged between 10 and $100 \mathrm{~g} / \mathrm{L}$ at the optimal $\mathrm{pH}$ and $298 \mathrm{~K}$. The $\mathrm{pH}$ value was between 2 and 11 . Nevertheless, the $\mathrm{pH}$ value of the wastewater was attuned to the $1 \mathrm{~N}$ aqueous solution of either $1 \mathrm{~N} \mathrm{H}_{2} \mathrm{SO}_{4}$ or $1 \mathrm{~N} \mathrm{NaOH}$, with regard to the primary value of $\mathrm{pH}$. The landfill leachate was made up of various components. Therefore, the parameter of the COD was regarded as the total adsorbate and the outcomes were recorded in terms of COD. The ratio of COD deduction was computed using the following equation:

$$
\% \text { COD removal }=\frac{C_{o}-C_{e}}{C_{e}} \times 100 .
$$

Kinetics study experiments were performed at $298 \mathrm{~K}$ with $C_{o}$ values of $1658 \mathrm{mg} / \mathrm{L}$ at an optimum lime dosage of $10 \mathrm{~g} / \mathrm{L}$ and $\mathrm{pH}$ of 2 . On the other hand, the carbon dosage was between $10 \mathrm{~g} / \mathrm{L}$ and $60 \mathrm{~g} / \mathrm{L}$. After 8 hours, the adsorbent was removed from the wastewater and was analysed to 


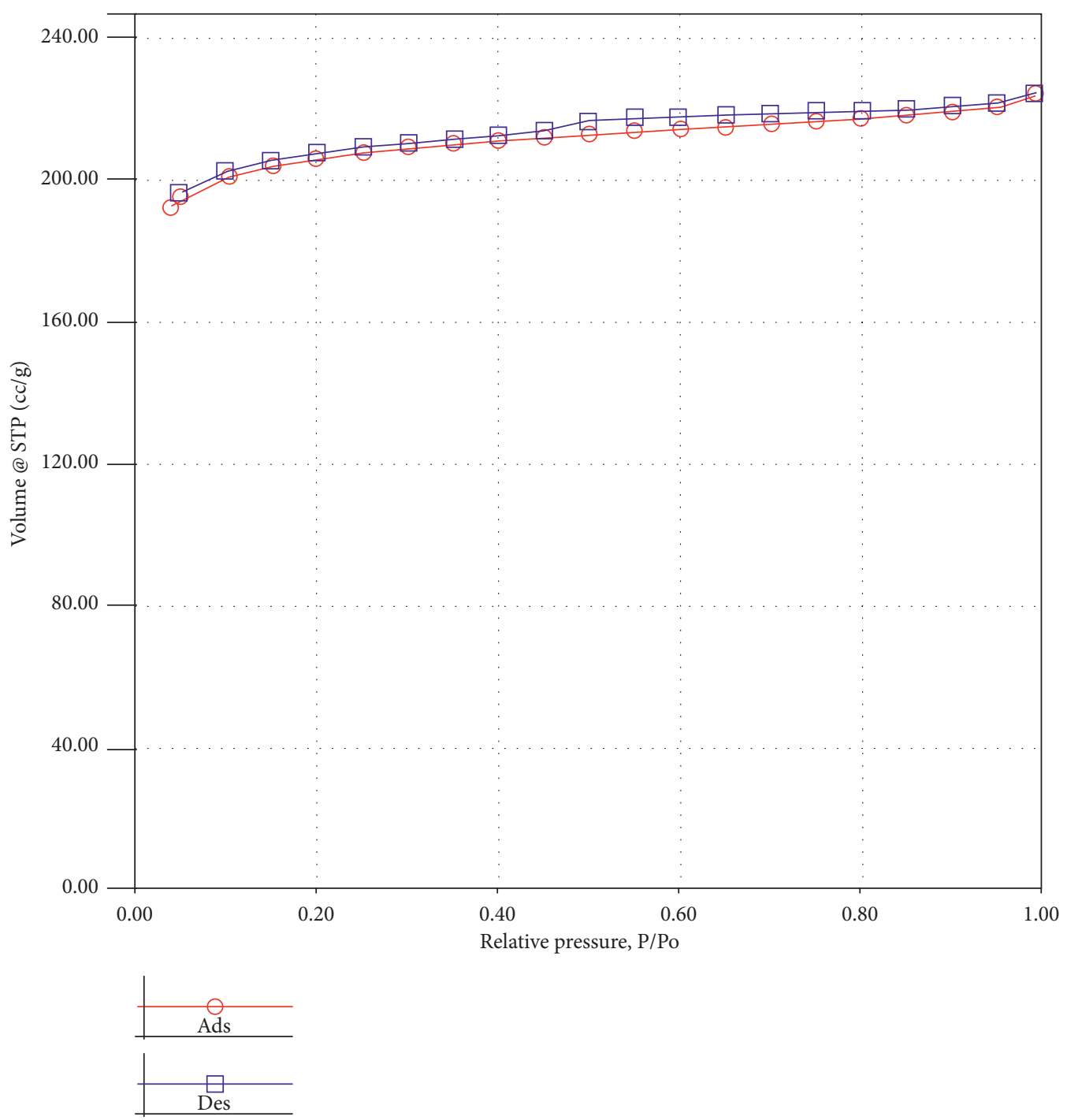

Figure 1: $\mathrm{N}_{2}$ adsorption and desorption isotherm at $77 \mathrm{~K}$ for the coconut granular-activated carbon.

examine the $\operatorname{COD} C_{t}$. At a given time $(t)$, among the COD, which was adsorbed onto the granular-activated carbon, $q_{t}$ (milligram per gram) was obtained as follows:

$$
Q_{t}\left(\frac{\mathrm{mg}}{\mathrm{g}}\right)=\frac{\left(C_{o}-C_{t}\right) V}{m}
$$

where $C_{\mathrm{o}}$ and $C_{t}(\mathrm{mg} / \mathrm{L})$ depict the primary COD and COD concentration at time $t$, respectively, $V$ symbolises the volume of the leachate $(\mathrm{L})$, and $m$ represents the weight of the adsorbent used $(\mathrm{g})$.

\section{Results and Discussion}

3.1. Characterisation of the Granular-Activated Carbon. Figure 1 shows the isotherm of nitrogen gas adsorption into the GAC. The GAC shows a high adsorption rate at relatively low pressure. This can be explained by the presence of micropores in the granular-activated carbon. This is because the isotherm is uniform and the hysteresis develops into low pressure. The surface area of the BET and the total pore volume of the granular-activated carbon are $672.94 \mathrm{~m}^{2} / \mathrm{g}$ and $1.277 \mathrm{~cm}^{3} / \mathrm{g}$, respectively.

Figure 2 shows the FTIR spectra of the coconut granularactivated carbon. Therefore, Figure 1 illustrates the characterisation outcomes of the Fourier transform infrared (FTIR) spectroscopy. The pinnacle of the broad-stretching adsorption is at $3228-3477 \mathrm{~cm}^{-1}$. This indicated the presence of $-\mathrm{NH}$ and bound $-\mathrm{OH}$ groups. On the other hand, the peaks of the $\mathrm{CH}$ - stretching vibration are at 2924 and 2858. The adsorption peak of group $\mathrm{C}=\mathrm{O}$ is at $1263 \mathrm{~cm}^{-1}$. The elemental analysis of the coconut activated carbon is shown in Table 2 from the SEM-EDX analysis.

Figure 3 shows the $\Delta \mathrm{pH}$ with a zero value. Therefore, the $\mathrm{pH}_{\mathrm{pzc}}$ for GAC is 10 . This signified that the solution has a $\mathrm{pH}$ value of 10 whereas the charge density of GAC is 0 . On the other hand, any solution that has a $\mathrm{pH}$ value higher than 10 is negative and positive when it is lower than 10 .

3.2. Lime and Acid Pretreatment. Raw partially stabilised leachate contained a high concentration of organic 


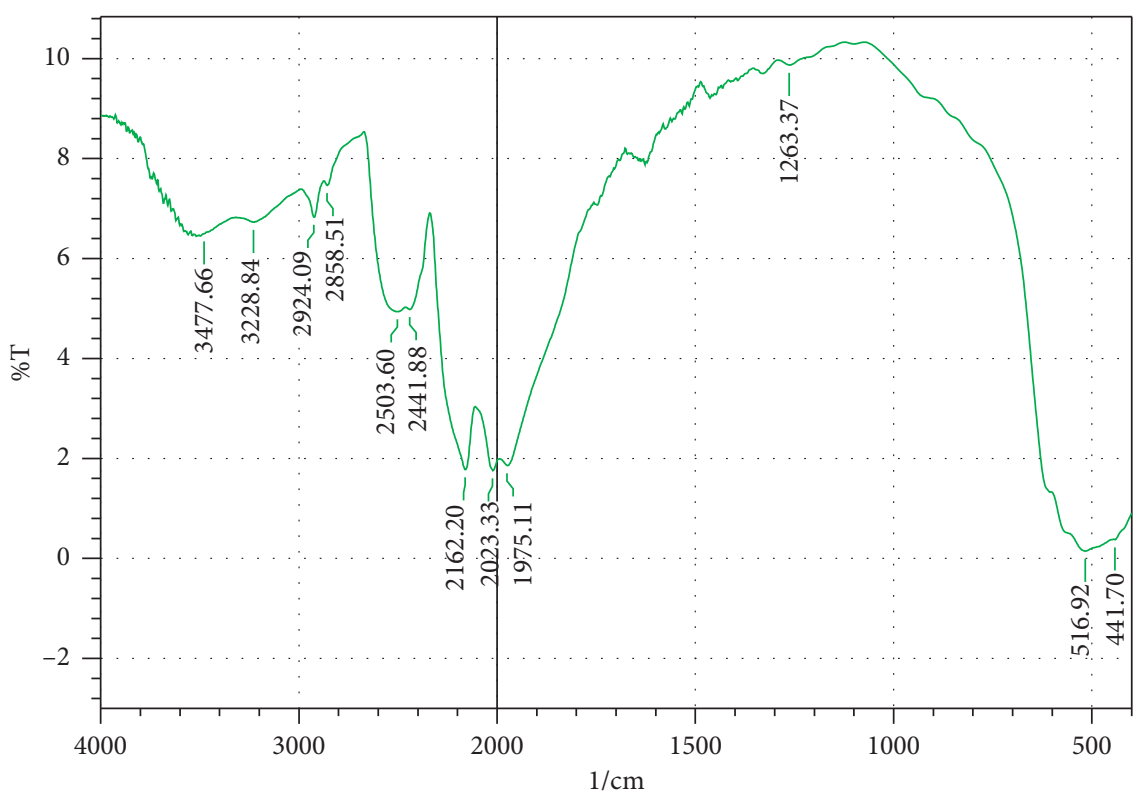

FIGURE 2: FTIR spectra of the coconut granular-activated carbon.

TABle 2: The EDX analysis of the coconut granular-activated carbon.

\begin{tabular}{lc}
\hline Element & GAC (weight \%) \\
\hline $\mathrm{C}$ & 92.55 \\
$\mathrm{O}$ & 3.89 \\
$\mathrm{~N}$ & 3.17 \\
$\mathrm{Al}$ & 0.40 \\
\hline
\end{tabular}

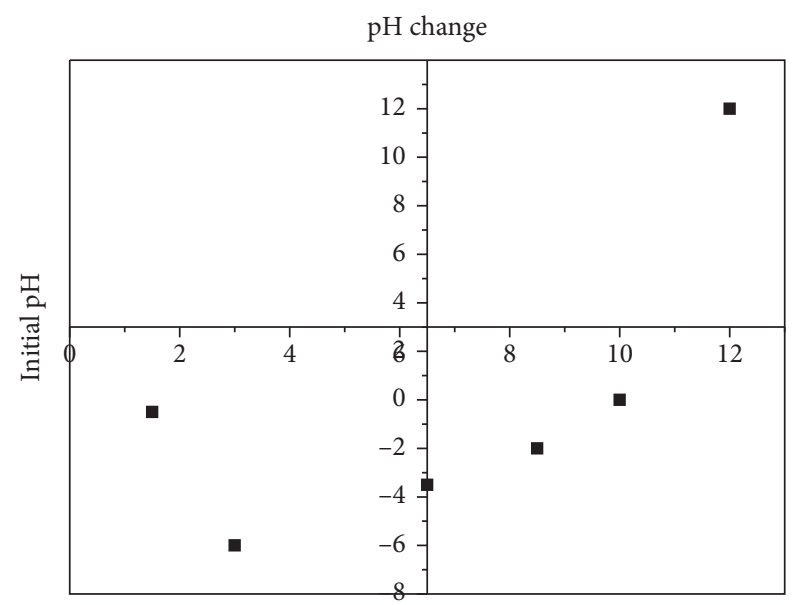

FIGURE 3: The zero charge point of the coconut granular-activated carbon.

substances particularly humic substances. In this study, the concentrations of organic substances were recorded as COD, and $\mathrm{UV}_{254}$ was used as the index of humic substances. The lime treatment removed some high molecular weight organic molecules such as humic substances prior to the adsorption for an optimised use of granular-activated carbon. Based on the literature, the dominant removal mechanism of humic substances via lime chemical treatment is coprecipitation [9]. Two types of coprecipitation mechanisms were involved in the coprecipitation of calcium carbonate and the organic molecules: (i) surface adsorption: the impurities were not integrated inside the crystal but were adsorbed on the exterior of the precipitate and (ii) occlusion: the impurities were adsorbed and physically contained in the crystal [9].

Initially, the lime treatment was introduced before the activated carbon adsorption to lower the organic contaminants before the process of activated adsorption of carbon to extend the life of the granular-activated carbon bed. Sulfuric acid was added to raise the $\mathrm{pH}$ of the lime-treated supernatant before the granular-activated carbon adsorption. This was done to achieve effective adsorption of the remaining organic molecules present in the lime-treated partially stabilised leachate. Solution $\mathrm{pH}$ influenced the adsorption of organic polyelectrolytes on carbon materials. It influenced the carbon surface charge and the ionisation or protonation of the electrolyte, which resulted in an increase of adsorption efficiency. After the lime and acid pretreatment in this study, there was a $90 \%$ removal of COD at a carbon dosage of $40 \mathrm{~g} /$ $\mathrm{L}, \mathrm{pH}$ of 2 , and lime dosage of $30 \mathrm{~g} / \mathrm{L}$.

3.3. Implications of Lime Dosage. Table 3 shows the study on the implications of lime dosage on the COD removal and the reduction of $\mathrm{UV}_{254}$ based on the lime dosage between $5 \mathrm{~g} / \mathrm{L}$ and $20 \mathrm{~g} / \mathrm{L}$. Therefore, an additional lime altered the colour of the leachate. When lime was added to the leachate, a brown precipitate was formed. Hence, the colour of the leachate changed from dark brown into light brown and light yellow with a lime dosage between 10 and $20 \mathrm{~g} / \mathrm{L}$. The result showed that the lime precipitation had a significant impact on the removal of organics from the leachates. For the optimum dose of lime, lime dose, the removal of COD reached $40.8 \%$ and the $U_{254}$ reduction was $55.97 \%$. This 
TABLE 3: Organics concentration in the effluent after lime treatment at different dosages.

\begin{tabular}{lcccc}
\hline Lime dosage & COD $(\mathrm{mg} / \mathrm{L})$ & $\mathrm{UV}_{254}\left(\mathrm{~cm}^{-1}\right)$ & COD removal $(\%)$ & $\mathrm{UV}_{254}$ reduction $(\%)$ \\
\hline 0 & 2800 & 15.92 & 0 & 38.1 \\
5 & 2000 & 9.86 & 28.6 & 47.0 \\
10 & 1800 & 8.43 & 35.7 & 55.97 \\
15 & 1658 & 7.01 & 40.8 & 52.9 \\
20 & 1600 & 6.92 & 56.53 \\
\hline
\end{tabular}

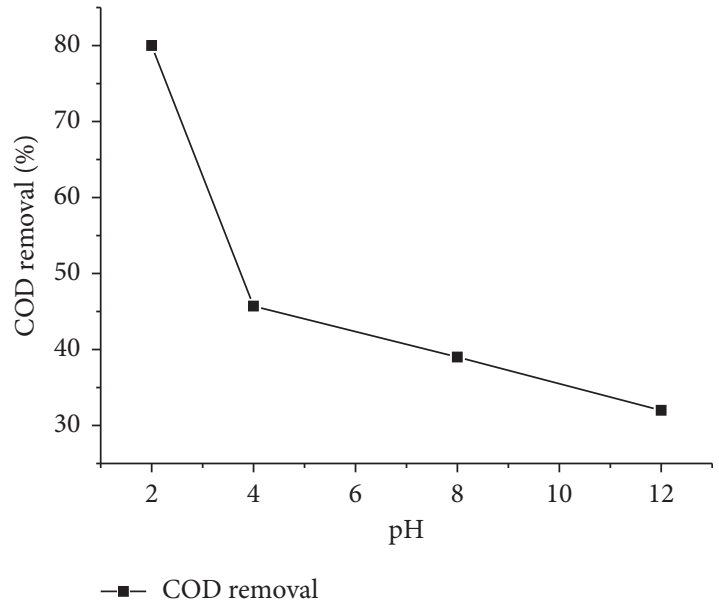

Figure 4: Effect of $\mathrm{pH}$ on COD removal using GAC (carbon dosage $=30 \mathrm{~g} / \mathrm{L}$, contact time $=8 \mathrm{~h}$, initial $\mathrm{COD}=1658 \mathrm{mg} / \mathrm{L}$, and temperature $298 \mathrm{~K})$.

phenomenon was rapid and the removal of organic substances (acknowledged as COD) and humic substances (expressed as $\mathrm{UV}_{254}$ ) started immediately after the CACO3 crystals started precipitating.

3.4. Effect of Initial $p H$. The residual, which was obtained after lime and acid pretreatment, possessed a COD of $1658 \mathrm{mg} / \mathrm{L}$. It was subsequently exposed to research works based on group adsorption via GAC. The implications of $\mathrm{pH}$ for the acid pretreatment on the efficiency of COD removal were carried out based on the varying $\mathrm{pH}$ while the other measurements remained constant. Therefore, the $\mathrm{pH}$ varied between 2 and 12 with an additional $\mathrm{H}_{2} \mathrm{SO}_{4}$ and $1 \mathrm{~N} \mathrm{NAOH}$ as per requirements. Nevertheless, the dosage of the adsorbent $(30 \mathrm{~g} / \mathrm{L})$, contact time $(t=8 \mathrm{~h})$, and temperature ( $T=298 \mathrm{~K}$ ) were kept constant. The introductory tests of the lime and acid pretreated partially stabilised leachate via GAC adsorption showed that the value of the COD was constant for more than an $8 \mathrm{~h}$ contact time. This proved that the $8 \mathrm{~h}$ contact time guaranteed the equilibrium of the wastewater with GAC. Figure 4 shows the effect of initial $\mathrm{pH}$ on the removal of COD by GAC.

The $\mathrm{pH}$ value of 2 depicted an increased removal efficiency of $76.2 \%$. However, the $\mathrm{pH}$ value of 12 represented a low removal efficiency of $38.7 \%$. The COD removal efficiencies decreased with the increasing $\mathrm{pH}$ of the pretreated leachate. Additionally, similar trends of $\mathrm{pH}$-dependent adsorption had been observed in other research studies in comparison with the carbonaceous adsorbents. Wang and

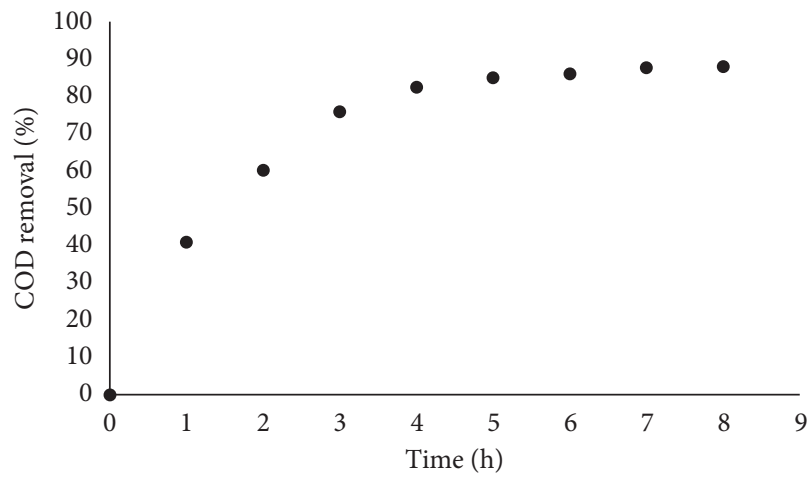

Figure 5: COD removal based on GAC with contact time (GAC dosage $=20 \mathrm{~g} / \mathrm{L}$, lime dosage $=10 \mathrm{~g} / \mathrm{L}$, contact time $=8 \mathrm{~h}$, initial $\mathrm{COD}=1658 \mathrm{mg} / \mathrm{L}$, and temperature $25^{\circ} \mathrm{C}$ ).

Zhu (2007) investigated the adsorption of humic acid to the fly ash-derived activated carbon and observed a decreased adsorption with elevated $\mathrm{pH}$ values as a result of the electrostatic repugnance to the adsorbent surface [10]. According to Chen and Wu (2004), pH-mediated hydrophobicity is a major factor that causes the adsorption of $\mathrm{pH}$ dependent organic molecules on the activated carbon [11]. The $\mathrm{pH}$ solution is an imperative aspect, which influences the adsorption of frail organic polyelectrolytes on carbon materials as a result of the electrostatic relationship between the adsorbent and adsorbate.

This is because the $\mathrm{pH}$ solution controlled the surface charge of the carbon and the ionisation of the polyelectrolyte. When the $\mathrm{pH}$ solution is lower than the $\mathrm{pH}_{\mathrm{pzc}}$, the surface charge of the activated carbon is positive. On the other hand, when the $\mathrm{pH}$ solution is higher than the $\mathrm{pH}_{\mathrm{pzc}}$, the surface charge of the activated carbon is negative. The $\mathrm{pH}_{\mathrm{pzc}}$ value of the GAC in the present study is 9.7. Therefore, the low COD removal efficiency at high $\mathrm{pH}$ stemmed from the repugnance between the negatively charged carbon surface and the anions from the organic molecules, which is dissociated at a high $\mathrm{pH}$.

3.5. Impact of Contact Time. Figure 5 shows the impact of contact time on the COD removal via the adsorption of GAC from the pretreated lime and subsequent acid at a GAC dosage of $30 \mathrm{~g} / \mathrm{L}$, lime dosage of $10 \mathrm{~g} / \mathrm{L}$, and $\mathrm{pH}$ of 2 , respectively. The adsorption of COD was fast for the first 3 hours with a $70 \%$ adsorption rate of COD removal. After 4 hours, the COD adsorption reached a plateau. After $8 \mathrm{~h}$, COD removal was at $87.9 \%$. This resulted from the limited dynamic platforms of the GAC surface, and therefore, it becomes saturated by the adsorbed organic compounds [12]. 
TABLE 4: The concentration of the organics in the effluent post-GAC adsorption.

\begin{tabular}{|c|c|c|c|c|}
\hline \multicolumn{5}{|c|}{ Concentration in the effluent } \\
\hline \multirow{2}{*}{ Dosage } & \multicolumn{2}{|c|}{ Lime and acid pretreated } & \multicolumn{2}{|c|}{ Acid pretreated } \\
\hline & $\mathrm{COD}(\mathrm{mg} / \mathrm{L})$ & $\mathrm{UV}_{254}$ & COD & $\mathrm{UV}_{254}$ \\
\hline 0 & 1658 & 5.45 & 2160 & 8 \\
\hline 2 & 500 & 1.6 & 1746 & 5.49 \\
\hline 4 & 136 & 0.31 & 950 & 2.89 \\
\hline 6 & 108 & 0.2 & 510 & 1.76 \\
\hline 8 & 80 & 0.15 & 300 & 1.04 \\
\hline 10 & 75 & 0.13 & 250 & 0.98 \\
\hline
\end{tabular}

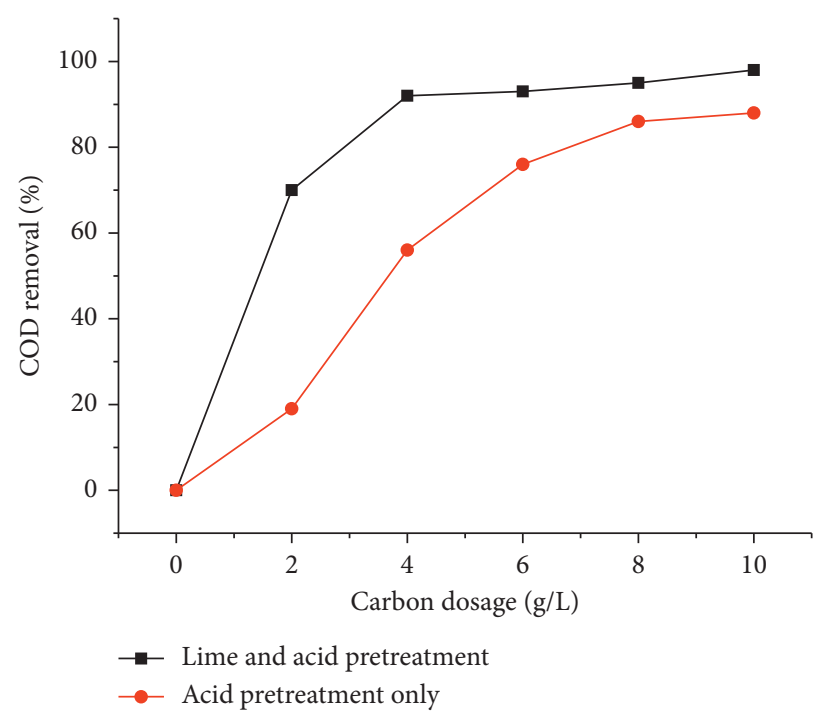

FIGURE 6: Effect of carbon dosage on the COD removal of acid pretreated only and lime and subsequent acid pretreated partially stabilised leachate.

TABLE 5: Kinetic constants for the adsorption of COD from pseudo-second-order kinetics.

\begin{tabular}{lcccc}
\hline \multirow{2}{*}{ Carbon dosage $(\mathrm{g} / \mathrm{L})$} & \multicolumn{3}{c}{ Kinetic constant } \\
& $q_{\mathrm{e}}(\exp )(\mathrm{mg} / \mathrm{g})$ & $q_{\mathrm{e}}($ calculated) $(\mathrm{mg} / \mathrm{g})$ & $K_{\mathrm{s}}$ & $R^{2}$ \\
\hline 10 & 110.8 & 123.46 & $8.3 \times 10^{-3}$ & 126.51 \\
30 & 49.27 & 53.19 & 0.0245 & 6.9716 \\
60 & 27.78 & 25.46 & 0.093 & 0.9812 \\
\hline
\end{tabular}

3.6. Efficiency Comparison of Organic Removal with Lime and Acidification Pretreatment. The efficiency of GAC dosage with lime and subsequent acid pretreatment was studied based on the varying dosages of GAC between 10 and $100 \mathrm{~g} /$ $\mathrm{L}$, with an initial leachate COD value of $1658 \mathrm{mg} / \mathrm{L}$ and $\mathrm{pH}$ of 2. Besides, it also had a lime dosage value of $10 \mathrm{mg} / \mathrm{L}$ at 298 K. Nevertheless, the effect of acid pretreatment dosage was studied based on the multiple dosages of GAC between 10 and $100 \mathrm{~g} / \mathrm{L}$ in which the leachate possessed an initial COD concentration of 2160 at $\mathrm{pH} 2$ at $298 \mathrm{~K}$.

The organic substances' concentration post-GAC adsorption was recorded in terms of COD and $\mathrm{UV}_{254}$. Therefore, Table 4 shows the concentrations of organic substances (expressed as COD and $\mathrm{UV}_{254}$ ) after adsorption with granular-activated carbon. Figure 6 shows that the removal of COD had increased sharply with the increase in the dosage of the adsorbent from $20 \mathrm{~g} / \mathrm{L}$ to $40 \mathrm{~g} / \mathrm{L}$. As shown in Figure 6, the percentage of the COD removed had increased with the cumulating dosage of carbon. This may result from the increased sum of the activated carbon's surface area because additional activated carbon was added into the solution. Hence, more active sites are available for the adsorption of COD from the aqueous solution [12]. Finally, this study achieved the point of equilibrium at approximately $40 \mathrm{~g} / \mathrm{L}$ of the carbon dosage for the optimum $90 \%$ COD removal for lime and acid pretreated partially stabilised leachate and approximately $80 \mathrm{~g} / \mathrm{L}$ of carbon dosage for the optimum $80 \%$ COD removal.

This study revealed that the partially stabilised leachate which was pretreated with lime and subsequent acid treatment has higher removal efficiency with specific regard to pretreated partially stabilised leachate. The additional 


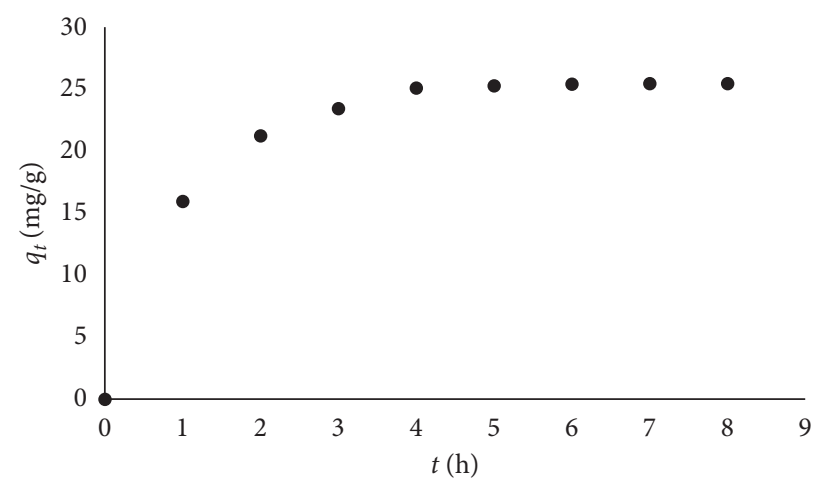

FIgure 7: Changes in organic COD versus adsorption at a GAC dose of $6 \mathrm{~g} / \mathrm{L}$.

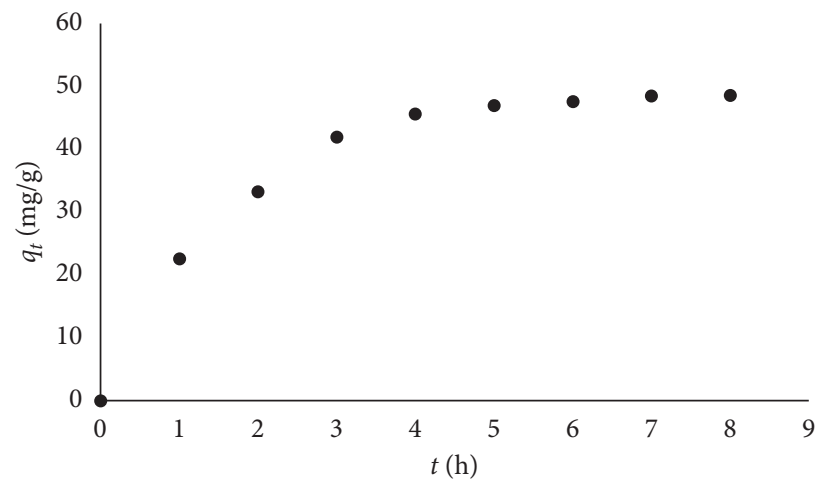

FIgURE 8: Changes in organic COD versus adsorption at a GAC dose of $3 \mathrm{~g} / \mathrm{L}$.

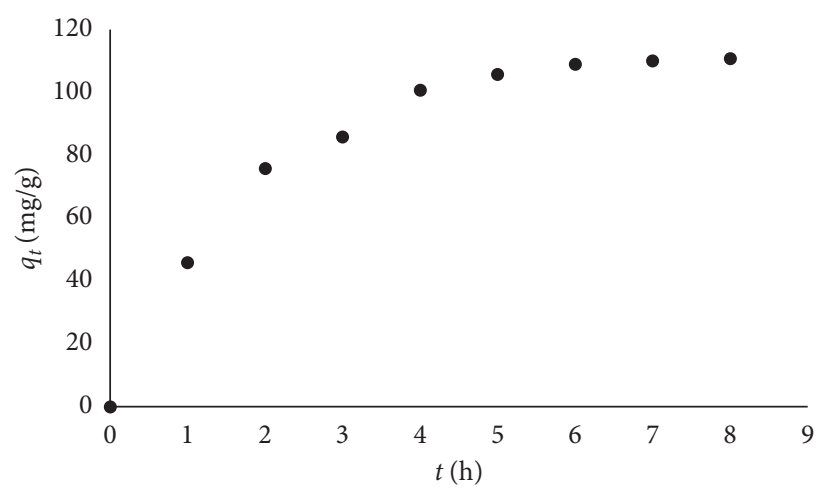

FIgure 9: Changes in organic COD versus adsorption at a GAC dose of $1 \mathrm{~g} / \mathrm{L}$.

effect of lime prior to the granular-activated carbon resulted in an imperative decrease of the organic compounds that existed in the partially stabilised leachate. Therefore, this reduced the amount of carbon dosage needed to achieve the desired treatment efficiency. Next, pretreating stabilised leachate with alum coagulation before the activated carbon adsorption had removed $80 \%$ of the COD [13]. Besides that, Li et al. [14] stated that it had improved the adsorption residual of organic compounds after the coagulation of activated carbon. Table 4 shows that if the dosage of the carbon increases, both the COD and $\mathrm{UV}_{254}$ also decrease. However, lime and acid pretreated partially stabilised leachate was more effective than the acid pretreated partially stabilised leachate. Additionally, $\mathrm{UV}_{254}$ of the lime and acid pretreated was lower than the acid pretreated $U_{254}$ because the humic substances were removed during the lime treatment stage.

3.7. Adsorption Kinetics. This study had experimented with the pseudo-second-order kinematic models for its capacity to signify the kinematics of adsorption from the pretreated lime and acid and the partially stabilised leachate via the GAC adsorption of different dosages of carbon. The explorative data based on the measurement of COD were tailored to distinctive paradigms (pseudo-first-order and 
TABLE 6: Elemental analysis of the generated sludge via EDX.

\begin{tabular}{lc}
\hline Element & Mass (\%) \\
\hline Carbon & 9.03 \\
Nitrogen & 2.11 \\
Oxygen & 43.16 \\
Fluorine & 0.44 \\
Magnesium & 0.21 \\
Calcium & 46.39 \\
Mercury & 0.08 \\
\hline
\end{tabular}

TABLE 7: Results of the toxicity leaching procedure.

\begin{tabular}{lr}
\hline Parameters & Values $(\mathrm{mg} / \mathrm{L})$ \\
\hline $\mathrm{Pb}$ & Not detected $(<0.1)$ \\
$\mathrm{Cu}$ & 1.2 \\
$\mathrm{Cd}$ & Not detected $(<0.1)$ \\
$\mathrm{Cr}$ & Not detected $(<0.1)$ \\
$\mathrm{Zn}$ & Not detected $(<0.1)$ \\
\hline
\end{tabular}

TABLE 8: Cost approximation of the treatment.

\begin{tabular}{|c|c|c|c|}
\hline & Lime & Sulfuric acid & Granular-activated carbon \\
\hline Unit cost & $\$ 200 / 907 \mathrm{~kg}$ & $\$ 100 / 543.7 \mathrm{~L}$ & $\$ 1200 / 907 \mathrm{~kg}$ \\
\hline Chemical/material consumption & $0.01 \mathrm{~kg}$ & $0.120 \mathrm{~L}$ & $0.03 \mathrm{~kg}$ \\
\hline Chemical cost per litre of COD treated leachate & $\$ 0.0022 / \mathrm{L}$ & $\$ 0.022 / \mathrm{L}$ & $\$ 0.0397 / \mathrm{L}$ \\
\hline Total chemical cost to treat below COD discharge limit $(<400)$ & & $\$ 0.0$ & \\
\hline
\end{tabular}

pseudo-second-order kinetics). As a result, this study predicted that the pseudo-second-order kinematics produced a comprehensive account of the development of the adsorption based on the $R^{2}$ values for the pseudo-second-order's $\left(R^{2}\right)$ linear forms. Hence, the first-order model was not used as a result of its inadequate fixture.

The adsorption of organics into the granular-activated carbon of the lime and the subsequent pretreated partially stabilised acid leachate was followed by pseudo-secondorder kinetics:

$$
\frac{t}{q_{t}}=\frac{1}{k_{2} q_{e}^{2}}+\left(\frac{1}{q_{e}}\right) t,
$$

where $q_{t}$ is the quantity of organic COD adsorbed per unit mass of adsorbent at a time, $t(\mathrm{mg} / \mathrm{g}) ; q_{\mathrm{e}}$ is the amount of COD organics adsorbed per unit mass of adsorbent at the symmetrical situations $(\mathrm{mg} / \mathrm{g})$; the constant $k$ is the rate of adsorption ( $\mathrm{g} / \mathrm{mg} \mathrm{h})$; and $t$ is time (h). The symmetrical ability of adsorption $\left(q_{e}\right)$ and the primary adsorption pace were ascertained based on the linear fixture of the stagnant $\left(K_{s}\right)$ pseudo-second-order investigational data. Table 5 summarises the adsorption kinematic strictures derived from the graphs of the kinetic model. On the other hand, Figures 7-9 show the relationship between organic adsorption and time for the varying doses of carbon. The denomination of the adsorbed experimental COD, $q_{e}$, exp, was relatively similar to the adsorbed computed COD, $q_{e}$, cal. Therefore, pseudo-second-order kinetics could be used to represent the adsorption process. Table 5 shows that the $q_{e}$ values depend on the dosage of the granular-activated carbon, which was in the range of $110.8-27.8 \mathrm{mg} / \mathrm{g}$. Although the removal efficiency increased with the increasing dosage of carbon, the capacity of adsorption, $q_{e}$, decreased with the increasing dosage of the granular-activated carbon. This resulted from the inclined levels of concentration between the diluted adsorbate in the partially stabilised leachate and on the surface of the adsorbent. This had ultimately decreased the number of organics adsorbed based on unit weight by the activated carbon [12].

3.8. Study on the Disposable Generated Sludge. Table 6 shows the elemental analysis of the generated sludge, which is comprised of the inorganically triggered level of calcium carbonate and of organic molecules such as the humic substances that coprecipitated with it. The lime treatment process generated approximately $180 \mathrm{ml}$ sludge per litre of the leachate. Nonetheless, it was not feasible to dispose of this sludge via the process of combustion as a result of its low concentration. Therefore, it was a viable option to dispose of the sludge at the landfill. Table 7 shows the results of the precipitated phase generated sludge, which was collected and subjected to the toxicity leaching procedure (TCLP). This procedure was done to determine the feasibility of disposal at the municipal solid waste facilities. Renou (2009) suggested a similar disposal technique and concluded that the stability of the humic acid fixation based on the generated sludge is more than $90 \%$ of permanent insolubilisation. This means that the storage of the generated sludge at MSWF has no influence on the characteristics of the newly generated leachates. 
3.9. Cost Estimation of the Combined Process. Table 8 depicts the cost approximation of the combined process. Additionally, this study considered the industrial-grade price of the chemicals. Therefore, the results showed that the combined process incurred a total cost of $\$ 0.0639 / \mathrm{L}$ of the treated wastewater.

\section{Conclusion}

The lime and acid pretreatment before the granular-activated carbon adsorption had removed the significant amount of COD from the partially stabilised leachate. Therefore, the lime pretreatment removed $42.8 \%$ of the raw COD partially stabilised leachate. High removal efficiencies (>90\%) at lower carbon dosage were achieved via the lime and acid pretreatment. As a result, the equilibrium was achieved within 8 hours. Acid pretreatment after lime treatment enhanced the adsorption of organics significantly onto the granular-activated carbon, which potentially extended the lifespan of the activated carbon. The kinetic models of the process of adsorption were followed by the pseudo-second-order degree kinetics.

\section{Data Availability}

The data used to support the findings of this study are available from the corresponding author upon request.

\section{Disclosure}

The authors were completely responsible for the subject matter of this article.

\section{Conflicts of Interest}

The authors of this research have no conflicts of interest.

\section{Acknowledgments}

The authors wish to thank the Department of Chemical Engineering, Universiti Malaysia Sarawak, for providing the facility for this research.

\section{References}

[1] M. J. K. Bashir, H. A. Aziz, M. S. Yusoff, S. Q. Aziz, and S. Mohajeri, "Stabilized sanitary landfill leachate treatment using anionic resin: treatment optimization by response surface methodology," Journal of Hazardous Materials, vol. 182, no. 1-3, pp. 115-122, 2010.

[2] A. A. Tatsi, A. I. Zouboulis, K. A. Matis, and P. Samaras, "Coagulation-Flocculation pretreatment of sanitary landfill leachates," Chemosphere, vol. 53, no. 7, pp. 737-744, 2003.

[3] E. S. K. Chian and F. B. Dewalle, Treatment of Leachate from Landfills, Solid and Hazardous Waste Research Laboratory, Cincinnati, OH, USA, 1974.

[4] A. Garg, I. M. Mishra, and S. Chand, "Effectiveness of coagulation and acid precipitation processes for the pre-treatment of diluted black liquor," Journal of Hazardous Materials, vol. 180 , no. $1-3$, pp. 158-164, 2010.

[5] S. Dhakhwa, S. Bandhyopadhyay, and A. Garg, "Removal of color and COD from synthetic papermill effluent using coagulation/ acid precipitation process," Journal of Indian Pulp \& Paper Technical Association, vol. 23, no. 2, pp. 187-192, 2011.

[6] V. Oloibiri, I. Ufomba, M. Chys, W. Audenaert, K. Demeestere, and S. W. Van Hulle, "Treatment of landfill leachate by coupling coagulation-flocculation or ozonation to granular activated carbon adsorption," Communications in Agricultural and Applied Biological Sciences, vol. 80, pp. 57-62, 2015.

[7] I. K. Erabee, A. Ahsan, B. Jose et al., "Adsorptive treatment of landfill leachate using activated carbon modified with three different methods," KSCE Journal of Civil Engineering, vol. 22, no. 4, pp. 1083-1095, 2018.

[8] R. P. Chavez, E. C. C. Pizarro, and Y. L. Galiano, "Landfill leachate treatment using activated carbon obtained from coffee waste," Sanitary Engineering Journal, vol. 24, no. 4, pp. 833-842, 2019.

[9] S. Renou, S. Poulain, J. G. Givaudan, C. Sahut, and P. Moulin, "Lime treatment of stabilized leachates," Water Science and Technology, vol. 59, no. 4, pp. 673-685, 2009.

[10] S. Wang and Z. H. Zhu, "Humic acid adsorption on fly ash and its derived unburned carbon," Journal of Colloid and Interface Science, vol. 315, no. 1, pp. 41-46, 2007.

[11] J. P. Chen and S. Wu, "Simultaneous adsorption of copper ions and humic acid onto an activated carbon," Journal of Colloid and Interface Science, vol. 280, no. 2, pp. 334-342, 2004.

[12] P. S. Kumar, S. Ramalingam, C. Senthamarai, M. Niranjanaa, P. Vijayalakshmi, and S. Sivanesan, "Adsorption of dye from aqueous solution by cashew nut shell: studies on equilibrium isotherm, kinetics and thermodynamic of interactions," Desalination, vol. 261, no. 1-2, pp. 52-60, 2010.

[13] C. Papastavrou, D. Mantzavinos, and E. Diamadopoulos, "A comparative treatment of stabilised landfill leachate: coagulation and activated carbon adsorption vs. Electrochemical oxidation," Environmental Technology, vol. 30, p. 14, 2009.

[14] W. Li, T. Hua, Q. Zhou, S. Zhang, and F. Li, "Treatment of stabilized landfill leachate by the combined process of coagulation/flocculation and powder activated carbon adsorption," Desalination, vol. 264, no. 1-2, pp. 56-62, 2010. 